\title{
Traditional learning approach versus gamification: an example from psychology
}

\author{
Limniou, Maria ${ }^{a}$ and Mansfield, Rosie ${ }^{b}$ \\ ${ }^{\mathrm{a}}$ School of Psychology, University of Liverpool, UK, ${ }^{\mathrm{b}}$ Manchester Institute of Education, \\ University of Manchester, UK.
}

\begin{abstract}
Teaching research methods and statistics in Psychology is a known pedagogic challenge due to students'varied mathematical aptitude, prior knowledge and attitudes towards modules. The aim of this investigation was to study student perspectives of an interactive learning approach for the first year practical class of a "Research Methods and Statistics" psychology module based on problems and games. The approach was developed by integrating problem-based learning and games supported by Kahoot and PollEverWhere (Web 2.0 applications). Two groups of first year psychology students (20 persons per group) attended practical classes based on an interactive and a traditional approach but following a different attending order (1. interactive and 2. traditional approach or vice versa) and completed two online surveys. Overall, the interactive approach was perceived to significantly improve student learning experience by promoting active and collaborative learning though the use of real research study applications and formative feedback.
\end{abstract}

Keywords: research methods; problem-based; game-based; active learning; Web 2.0; formative feedback 


\section{Introduction}

Researchers have studied the importance of the research methods and statistics integration into a psychology module, as students are not eager to follow relevant modules (Rajecki et al., 2005). The willingness of Psychology students to follow these modules is related to three broad perspectives: mathematical aptitude and prior knowledge of students, affective and attitudinal factors and pedagogic approaches (Mulhern \& Wylie, 2006). Many Psychology students experience 'statistics anxiety' (Wilson, 2013) and it is widely acknowledged that teaching statistics in Psychology is a pedagogic challenge due to heterogeneous cohorts with varied mathematical ability (Lalonde \& Gardner, 1993; Mulhern \& Wylie, 2004). Tishkovskaya and Lancaster (2012) reviewed the challenges of statistical education and provided an overview of suggested strategies and techniques for developing research-based statistics courses. For example, they proposed the use of active and collaborative problem solving, technology and online resources to promote statistical reasoning, interactive activities with feedback and the use of real world examples. Wilson (2013) reported that a flipped classroom approach could enhance the learning of statistics allowing students to "do statistics" and solve problems in an environment where they can get immediate feedback (p. 197).

Wiggins, Chiriac, Abbad, Pauli and Worrell (2016) highlighted the lack of the extent integration of problem-based learning approach into Psychology modules, although it could allow students to apply knowledge across contexts and to real world problems and to understand a topic through the collaboraton with their peers enhancing their problem solving skills (Hmelo-Silver, 2004). Despite the difference in problem-based activities, class size and evaluation, a problem-based approach in research methods and statistics modules can increase students' motivation, engagement (Elder, 2016) and student performance (Karpiak, 2011). Boyle, Connolly and Hainey (2011) suggested that the integration of games into education can provide contextualised, problem-based and interactive learning activities allowing students to learn through entertainment (Henderson, 2005). According to de Marcos et al., (2014) "gamification is the use of game elements and game-design techniques in non-game contexts, to engage people and solve problems" (p.82). It has been reviewed as an effective learning method, as it enhances student motivation, team work and collaboration (McLafferty et al., 2010) promoting learning in a nonthreatening and stress-reduced environment (Henderson, 2005).

McLoughlin and Lee (2007) have presented how the introduction of Web 2.0 technology could enhance learning by using a wide variety of tools in education to support student interaction, learning approaches and self-directions.Wang, Elvemo and Gamnes (2014) 
have advocated that the way of Web 2.0 applications are integrated into teaching and learning process has an impact on student engagement, learning, attention and contribution. The aim of this investigation was to compare student views following an interactive teaching approach based on (game-based) student response systems (Kahoot and PollEveryWhere) with a traditional way of teaching for first year research methods and statistics practical classes in a Psychology course. The hypothesis of this study was to investigate whether the interactive approach will significantly improve student learning experience compared with the traditional way of teaching.

\section{Method: Experimental conditions and participants}

Forty first year Psychology students participated in this investigation. The students were split into two groups. The first group (Group A) had firstly participated in the interactive learning approach and then attended the traditional approach, while the second group (Group B) had attended the practical classes with the opposite order. Two online questionnaires were distributed to them, one per learning approach. 32 students completed both questionnaires (Group A: $\mathrm{N}=14$, Group B: $\mathrm{N}=18$ ) which consisted of quantitative questions (0-10 agreement scale) and an open-ended question. The items of the questionnaire were inspired by the UK National Student Survey (NSS) (http://www.thestudentsurvey.com).

\section{Procedure: Description of the two learning approaches}

\subsection{Traditional learning approach}

Students were expected to attend a 90-minute practical class for a "Research Methods and Statistics" module each week in order to revise and apply knowledge from the relevant lecture on statistics. In the practical class, students were firstly presented with a brief introduction to the assumptions of the test and were given a simple hypothetical study example. They were asked to complete a few questions relating to the design, data level and statistical distribution. Also, they were asked to calculate descriptive and inferential statistics by hand using step-by-step instructions from a workbook. An example of how to write up the result in a report was provided and they completed summative weekly tasks in their own time by using SPSS. The design of this approach was aimed to support an idependent learning process in a small scale learning environment (20 students per class).

\subsection{Interactive learning approach based on (game) student response systems}

The teacher initially presented the theory behind the statistical analysis (e.g. independent samples t-test) and introduced the class to a real research problem, recently studied by 
researchers within the School. The whole class was split into smaller groups and they were encouraged to consider the rationale of the study and form an experimental hypothesis. They were given time to work together through questions relating to the presented research study.

Kahoot! was used as game-based student response system (Wang, 2015) allowing the groups of students to compete against one another while testing their knowledge. The groups could add a team name and compete against each other by answering the multiple choice questions as quickly as they could. Between each question the scoreboard was updated; the pause between questions gave the teacher a chance to discuss the correct answer with the class and to provide formative feedback (Figure 1).

Following the first activity, students were given an example set of data for the given research question and asked to fill in the blanks for hand calculations. The main focus of this activity was to get students to understand the mathematical underpinnings of the statistical analysis. Groups were then given screenshots of SPSS output to consider, based on different data for the same study example, and were instructed to work together to answer several questions regarding data handling and SPPS interpretation. PollEveryWhere was used as student response system (Shon \& Smith, 2011). Each student was encouraged to submit their responses on research design, hypotheses, data handling and SPSS output interpretation questions (Figure 2). The design of this approach was aimed to support an collaborative problem-based learning process in a small scale learning environment (20 students per class).

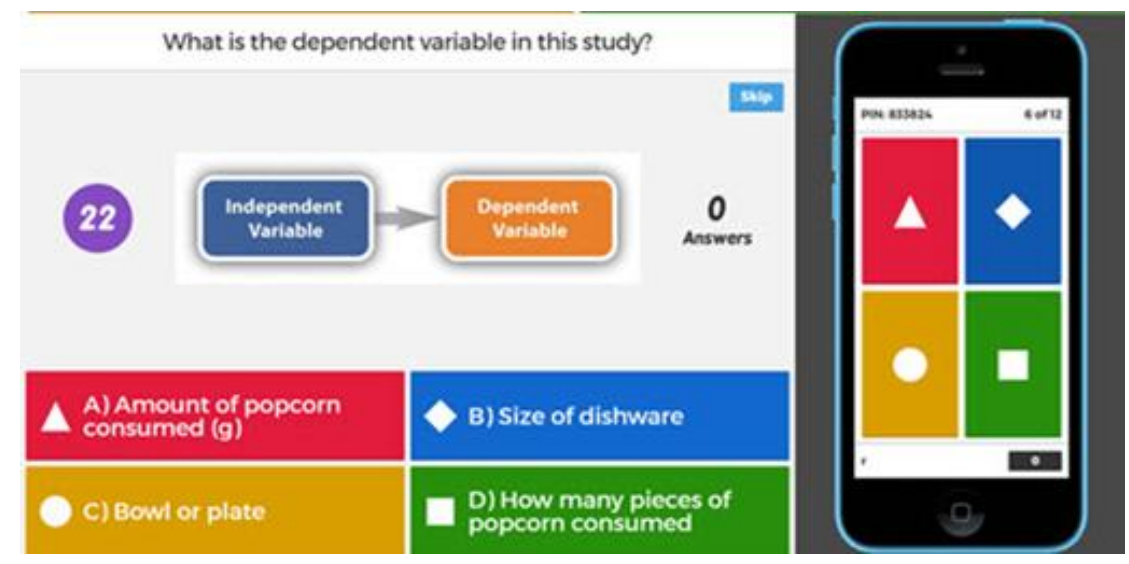

Figure 1: Screen shot from the Kahoot game 


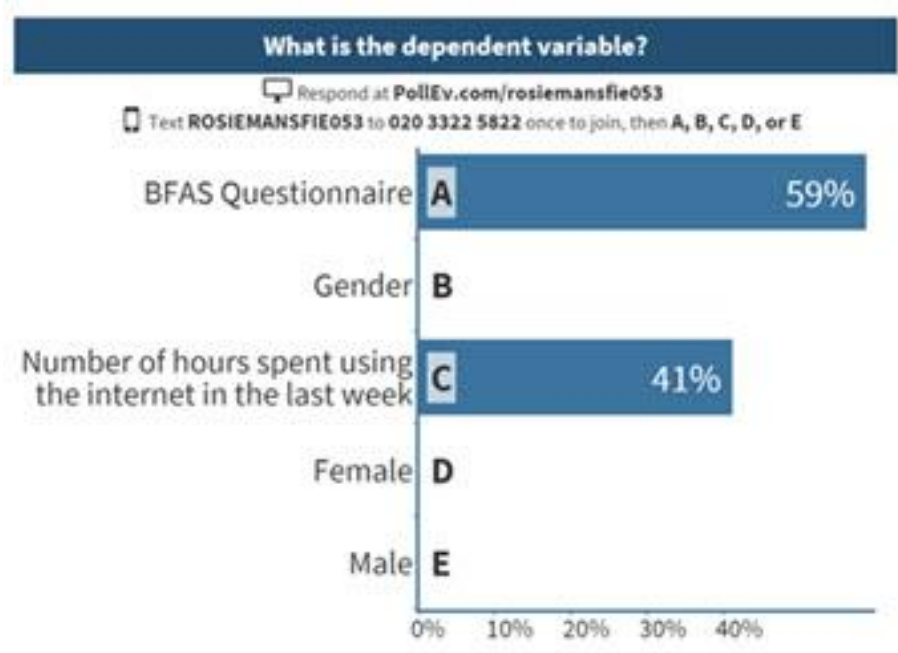

Figure 2. Example screenshot from the Poll Everywhere questions

\section{Results}

Table 1 shows the mean and the standard deviation values $( \pm \mathrm{SD})$ for the traditional and interactive learning approaches on items relating to the learning experience. A repeated measures MANOVA revealed a significant main effect of approach on learning experience $\mathrm{F}(1,30)=30.61, \mathrm{p}<.001, \eta p .2=.51$, such that students reported a significantly better learning experience for the interactive approach $(8.13 \pm 1.45)$ when compared with the traditional approach $(6.04 \pm 1.56)$. There was a significant item by approach interaction $\mathrm{F}(5$, $160)=10.00, \mathrm{p}<.001, \eta p .2=.25$, caused by students reporting that the interactive approach was significantly more interesting, intellectually stimulating, enjoyable and active and engaging $(\mathrm{p}<.001)$. 
Table 1. Means $( \pm$ SD) for the traditional and interactive learning approaches on items relating to the learning experience

\begin{tabular}{|c|c|c|}
\hline $\begin{array}{l}\text { To what extent would you say the traditional approach of } \\
\text { teaching year } 1 \text { practical classes/interactive approach } \\
\text { achieves the following }\end{array}$ & $\begin{array}{l}\text { Traditional } \\
\text { Approach }\end{array}$ & $\begin{array}{l}\text { Interactive } \\
\text { Approach }\end{array}$ \\
\hline Q1. Explaining research methods and statistics concepts & $7.00( \pm 1.81)$ & $7.44( \pm 1.83)$ \\
\hline Q2. Making practical class interesting & $5.16( \pm 2.17)$ & $8.41( \pm 1.70)$ \\
\hline $\begin{array}{l}\text { Q3. Making the practical class content intellectually } \\
\text { stimulating }\end{array}$ & $5.63( \pm 2.00)$ & $8.19( \pm 1.67)$ \\
\hline Q4. Enjoyability in the first year practical class & $6.06( \pm 2.18)$ & $8.28( \pm 1.69)$ \\
\hline Q5. Opportunities for a active and engaged learning approach & $5.56( \pm 2.03)$ & $8.41( \pm 2.08)$ \\
\hline Q6. Being organised and run smoothly & $7.72( \pm 1.53)$ & $8.59( \pm 1.50)$ \\
\hline $\begin{array}{l}\text { Q7. Providing constructive comments on student } \\
\text { contributions in the traditional/interactive practical class }\end{array}$ & $5.13( \pm 2.60)$ & $7.56( \pm 1.93)$ \\
\hline Q8. Preparing students for their exams & $6.56( \pm 1.97)$ & $7.53( \pm 1.44)$ \\
\hline
\end{tabular}

Furthermore, the interactive approach was perceived to be significantly more organised $(\mathrm{p}=.024)$ and provided more constructive feedback $(\mathrm{p}<.001)$. However, there was no significant difference between approaches in the extent to which research methods and statistics concepts were explained ( $p>05$ ). Finally, there was no significant approach by class interaction $\mathrm{F}(1,30)=.13, \mathrm{p}=.719, \eta \mathrm{p} .2=.00$, indicating that the effect of approach was not dependent on the class attending order (1. interactive and 2. traditional approach or vice versa). A related samples t-test also revealed that students perceived the interactive approach to better prepare them for examinations, when compared with the traditional learning approach, $t(31)=-2.14, p=.040$. Finally, they had the opportunitiy to leave any comments they might have about their first year practical classes (Table 2). 
Table 2. A sample of the student comments relating to the learning experience

I really enjoyed participating as a group and talking with the group to come to a joint decision and discussing ideas etc., I also really enjoyed the Poll Everywhere quiz at the end to test individual knowledge- this seems a really good way to allow you to engage on an individual level without having to put hands up etc. therefore making it more accessible for everyone. I felt that it was really engaging and put stats and methods into a very practical and memorable format where the relevance for future research and studies could be clearly seen and therefore the willingness to participate was higher.'

'The new collaborative approach is a significantly refreshing and exciting approach in teaching statistics and methodology...I developed a better understanding of the research being taken in the department .....I honestly enjoyed being presented with different types of tools and being able to make a decision on what would be best for this experiment......I did feel there was a lot more participation than in my normal seminar which was nice..... Poll Everywhere, Kahoot.it will absolutely increase participation in seminar groups. I was more likely to contribute answers since it was anonymous - this could have profound influence in allowing students with anxiety or shyness to add their answers'

I really enjoyed the new approach as it encouraged me [to] ask for help with the people on my table if I was struggling to understand something, I also felt that we were more engaged with our instructor as she was able to spread her time between four different tables instead of several smaller tables'

'I thought the Poll Everywhere aspect was very good - to actually test yourself and no one was embarrassed to answer'

\section{Discussion and conclusions}

The aim of this investigation was to study what impact an alternative learning approach based on (game) student response systems had on student experience compared with the traditional way of teaching for psychology research methods and statistics practical classes. Overall, students reported the interactive learning approach to be significantly more interesting, intellectually stimulating, enjoyable, engaging and organized. It provided students with more constructive feedback allowing themselves to express their views through a collaborative environment. The students stated they felt better prepared for their final examinations upon following the interative approach, as they felt that they better understood the research methods and statistics topics through the interaction with technology, problems and games. Another interesting point is related to the relationships between students and teachers. It seems that by supporting a teaching approach based on problem-based and game-based learning with the appropriate use of technology, the gap between teachers and students decreased allowing students to be more engaged and motivated with the learning process by expressing their thoughts. By solving problems and 
playing games to produce a research methodology rationale, students critically reflected on the statistical results process and they better understood the "repulsive" subject topic of research methods and statistics. Results suggested that by incorporating research-based, problem-solving and game-based learning approaches with technology students were not only active learners, but they enjoyed their learning time. The student views were not influenced by the order that they followed the two approaches.

The way that the interactive approach was designed was based on student difficulties within the domain of research methods and statistics rather than being technology-driven. For that purpose, a pedagological approach based on research-led activities along with a model of the pedagogical use of the tools were firstly designed. The choice of technology was in alignment with the design of the activities. For example, the choice of the Web 2.0 social media applications was made to support an approach which would be conducted in a relaxing and problem-based learning environment, allowing students to learn through entertainment and anonymous feedback. The learning activities were not designed to replace the traditional tasks or to integrate technology into a part the traditional learning approach, but they were designed to allow students to learn research methods and statistics through interactions with content, their peers, teachers and technology by using real research study examples. This learning approach could be determined as authentic, because it supported a combination of research methods and statistics domain subject with the "real world" scenarios in a problem- and game-based learning environment promoting active and collaborative learning process. Future research will be conducted on student research skill development and students' performance.

\section{References}

Boyle, E., Connolly, T.M., \& Hainey, T. (2011). The role of psychology in understanding the impact of computer games. Entertainment Computing, 2(2), 69-74.

de-Marcos, L., Domínguez, A., Saenz-de-Navarrete, J., \& Pagés, C. (2014). An empirical study comparing gamification and social networking on e-learning, Computers \& Education, 75(1), 82-91.

Elder, A D. (2015). Using a brief form of problem-based learning in a research methods class: perspectives of instructor and students. Journal of University Teaching and Learning Practice, 12(1), 8.

Henderson, D. (2005). Games: making learning fun. Annual Review of Nursing Education, 3, 165.

Hmelo-Silver, C.E. (2004). Problem-based learning: what and how do students learn? Educational Psychology Review, 16(3), 235-266.

Karpiak, C.P. (2011). Assessment of problem-based learning in the undergraduate statistics course. Teaching of Psychology, 38(4), 251-254. 
Lalonde, R.N., \& Gardner, R.C. (1993). Statistics as a second language? A model for predicting the performance in psychology students. Canadian Journal of Behavioural Science, 25(1), 108-125.

McLafferty, E., Dingwall, L., \& Halkett, A. (2010). Using gaming workshops to prepare nursing students for caring for older people in clinical practice. International Journal of Older People Nursing, 5(1), 51-60.

McLoughlin, C. and Lee, M.J.W. 2007. Social software and participatory learning: pedagogical choices with technology affordances in the Web 2.0 era. In ICT: Providing Choices for Learners and Learning: Proceedings Ascilite Singapore 2007, pp. 664-675. Retrieved from www.ascilite.org.au/conferences/singapore07/procs/mcloughlin.pdf at 19 January 2018.

Mulhern, G. \& Wylie, J. (2004). Changing levels of numeracy and other core mathematical skills among psychology undergraduates between 1992 and 2002. British Journal of Psychology, 95, 355-370.

Mulhern, G., \& Wylie, J. (2006). Mathematical prerequisites for learning statistics in psychology: assessing core skills of numeracy and mathematical reasoning among undergraduates. Psychology Learning \& Teaching, 5(2), 119-132.

Rajecki, D. W., Appleby, D., Williams, C. C., Johnson, K., \& Jeschke, M. P. (2005). Statistics can wait: career plans activity and course preferences of American psychology undergraduates. Psychology Learning \& Teaching, 4(2), 83-89.

Shon, H., \& Smith, L. (2011). A review of Poll Everywhere audience response system. Journal of Technology in Human Services, 29(3), 236-245.

Tishkovskaya, S., \& Lancaster, G.A. (2012). Statistical education in the $21^{\text {st }}$ century: a review of challenges, teaching innovations and strategies for reform. Journal of Statistics Education, 20(2), 1-24.

Wang, A. I., Elvemo, A. A., \& Gammes, V. (2014). Three social classrooms applications to improve student attitudes. Educational Research International, 259128, 14.

Wilson, S.G. (2013). The flipped class: a method to address the challenges of an undergraduate statistics course. Teaching of Psychology, 40(3), 193-199.

Wiggins, S., Chiriac, E.H., Abbad, G.L., Pauli, R., \& Worrell, M. (2016). Ask not only 'what can problem-based learning do for psychology?' but 'what can psychology do for problem-based learning?' A review of the relevance of problem-based learning for psychology teaching and research. Psychology Learning \& Teaching, 15(2), 136-154. 